\title{
Case Report: Focused Shock Waves as a Treatment Option in Failed Rotator Cuff Calcification Surgery
}

\author{
Daniel Moya ${ }^{1}$
}

\section{Abstract}

Introduction: Focused extracorporeal shock wave treatment has emerged as an alternative therapy before invasive procedures when conservative treatment has failed in rotator cuff calcifications. It can also be used when surgery has failed.

Case Report: We report a case of failed surgery in which focused shock waves were used for treatment. We applied three sessions of focused electromagnetic waves (Dornier Compact Alpha) with an energy level of $0.20 \mathrm{~mJ} / \mathrm{mm} 2,2000$ pulses per sesión, every 2 weeks. The pain gradually disappeared and mobility was regaining. The radiographic control 2 months after the last session showed the total disappearance of the calcification. The end result was the complete disappearance of the symptoms.

Conclusión: The effectiveness of shock waves, their non-invasiveness, safety, and cost efficiency justify their use both as an option before an invasive technique and when surgery has failed in the treatment of rotator cuff calcifications.

Keywords: Rotator cuff calcifications, Shock waves, Failed surgery

\section{Introduction}

The presence of calcium deposits in the rotator cuff tendons is a relatively common condition. The prevalence of rotator cuff calcifications in an asymptomatic population has been reported between $2.7 \%$ [1] and $20 \%$ [2].

Codman [3] suggested that hypoxia could be responsible for the initiation of the process, but other authors have referred to genetic predisposition $[4,5,6,7,8]$, microtrauma [9], metabolic [10], and hormonal factors [11].

Uththoff [12] described a progression in local histological changes that coincide with clinical and radiographic findings.

Regarding the treatment of calcific rotator cuff tendonitis, decisions will be made in light of the evolutionary stage, the degree of symptoms, and the response to initial treatments. Although the natural history of the disorder tends towards its spontaneous resolution, the cycle can stagnate in any of its stages. It is in these situations that it is necessary to intervene in the process to calm the symptoms or even accelerate it's the resorption process.

Conservative treatment is the initial choice. When conservative treatment failed, the usual indication was invasive treatment, either mini-invasive or by surgery. Focused extracorporeal shock wave treatment (FESWT) has emerged as an alternative therapy prior to invasive procedures when conservative treatment has failed [13].

F-ESWT can also be used when surgery has failed. We present a failed case of surgery in which focused shock waves were used for treatment.

\section{Case Presentation}

A 43-year-old male presented with intense pain and limited mobility of his left shoulder. His profession as a dentist further complicated the situation, preventing him from working.

He initially consulte done year ago complaing moderate intermittent pain and limited range of motion. A calcification of the rotator cuff located in the supraspinatus was diagnosed (Fig. 1).Arthroscopic surgery was performed to remove the calcification with poor results.
I first met him 8 months after surgery reporting that the pain had not only not calmed down but had increased markedly. He had moderate deltoid atrophy. Active mobility was 90 degrees of anterior flexion, 10 degrees of external rotation, and internal rotation at L5 level. Passive mobility was limited by pain.

$\mathrm{X}$-rays showed that the calcification not only had not diminished with surgery, it appeared to be larger (Fig. 2).

It was decided to try with F-ESWT. We applied 3 sessions of focused electromagnetic waves (Dornier Compact Alpha) with an energy level of $0.20 \mathrm{~mJ} / \mathrm{mm} 2,2000$ pulses per-sesión, every 2 weeks.

In parallel, the patient was treated with Paracetamol $1 \mathrm{~g}$ up to every $6 \mathrm{~h}$ according to pain level, and a gentle and progressive program of home-based exercises.

The pain gradually disappeared and mobility was regaining. The radiographic control 2 months after the last session showed the total disappearance of the calcification (Fig. 3).

The end result was the complete disappearance of the symptoms.

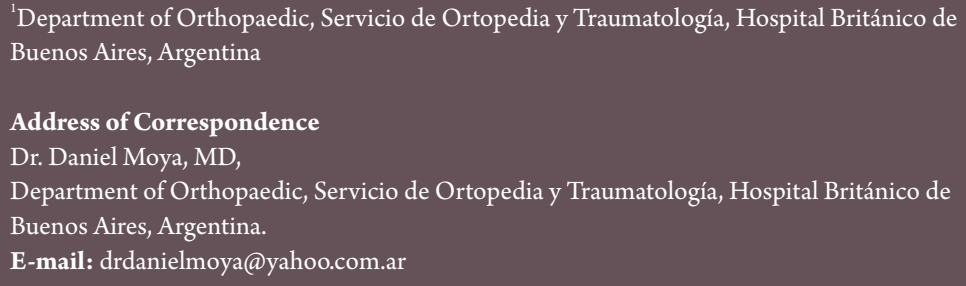

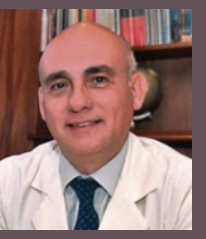

Dr. Daniel Moya

Submitted Date: 15 June 2021, Review Date: 15 July 2021, Accepted Date: 23 September 2021 \& Published: 31 December 2021

(c) 2021 by Journal of Regenerative Science |Available on www.jrsonweb.com | DOI:10.13107/jrs.2021.v01.i01.027

This is an open access journal, and articles are distributed under the terms of the Creative Commons Attribution-NonCommercial-ShareAlike 4.0 License (https://creativecommons.org/licenses/by-nc-sa/4.0/), which allows others to remix, tweak, and build upon the work non-commercially, as long as appropriate credit is given and the new creations are licensed under the identical terms. 


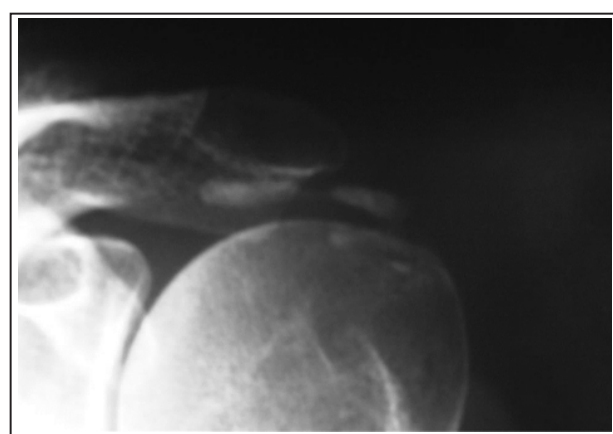

Figure 1: Preoperative X-ray showing Gärtner stage I calcium deposits located in the supraspinatus tendon.

\section{Discussion}

Codman [3] published a detailed description of the surgical procedure made by Painter. Both authors recommend surgery. Neer [14] mentioned that during his 1 st years in surgical practice the most frequent shoulder procedure was the excision of calcium deposits, on the other hand, during the past years of his practice he operated one or two cases per year despite dedicating himself only to shoulder surgery. Gschwend et al. [15] described three precise indications for surgery when treating rotator cuff calcifications: (a) symptomatic progression, (b) constant and unmanageable pain, and (c) failure of conservative treatment.

Surgery has a high rate of good results $[16$, 17] but is not without complications, slow recovery, and poor results $[14,18,19,20,21$, $22,23,24]$. The patient we present is a good example of this.

Neer [14] cautions that the postoperative recovery period in chronic cases is much longer than would be expected for a seemingly simple surgical gesture. McKendry et al. [19] reported 30\% persistence of pain at 12 postoperative weeks. Other authors [22, $23,24]$ agree with this and have reported that several months must pass after surgery for the patient to be totally asymptomatic.

Controversy exists regarding management of rotator cuff defects after calcific deposit removal [25, 26, 27, 28, 29]. Initially, it was not sutured but lately recognized authors recommended its closure in both open [27] and arthroscopic procedures [28]. Verhaegen et al. [25], reported persistent rotator cuff defects at 1 year on after arthroscopic needling of rotator cuff calcific deposits.

Performing or not acromioplasty is another controversial factor. Ellman [30] reported a reoperation rate of $19 \%$ in patients in whom

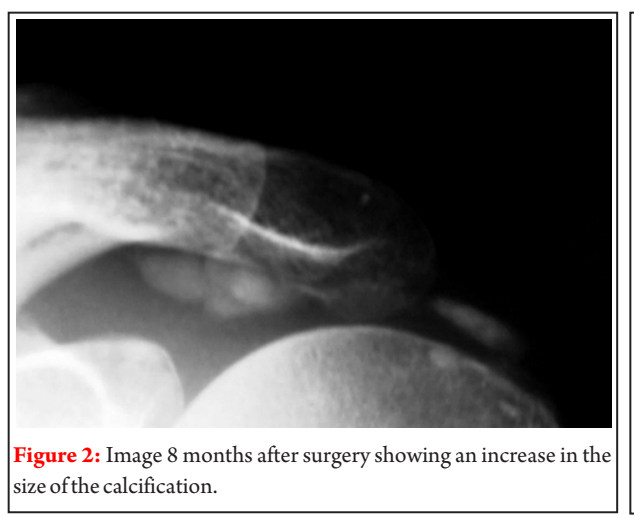

acromioplasty was not performed in the first procedure. On the other hand, Maier [31] stated that arthroscopic removal of calcific deposits of the supraspinatus tendon without acromioplasty yielded favorable outcomes and determined fast remission of pain regardless of acromial morphology.

Treatment by F-ESWT has emerged as an alternative when conservative treatment fails and prior to invasive procedures $[13,32]$. Gerdesmeyer et al. [33], in a multicenter randomized controlled trial, reported significantly better results in patients treated with F-ESWT, both low and high energy, compared with placebo, resulting in significant improvement with respect to pain, shoulder function, and calcium resorption in $86 \%$ in the high-energy group at 1 year compared with $37 \%$ in the low-energy group and $25 \%$ in the placebo ESWT group. Cosentino et al. [34], reported a significant increase in shoulder function, a decrease in pain compared with placebo, and calcium resorption of $71 \%$ by using F-ESWT, at 6 months. Hsu et al. [35], achieved good or excellent results in $87.9 \%$ of patients treated with high-energy F-ESWT.

Louwerens et al. [36] in a systematic review and meta-analysis about chronic calcific tendinopathies of the rotator cuff, concluded that "high-energy extracorporeal shock wave therapy is the most thoroughly investigated minimally invasive treatment option in the short-term to midterm and has proven to be a safe and effective

treatment."

Rompe et al. [37] and Rebuzzi et al. [38] compared F-ESWT with open and arthroscopic surgery in CTS, respectively. They concluded that the results are comparable and that high-energy

F-ESWTshould be the first choice when conservative treatment has failed, because of its noninvasiveness.

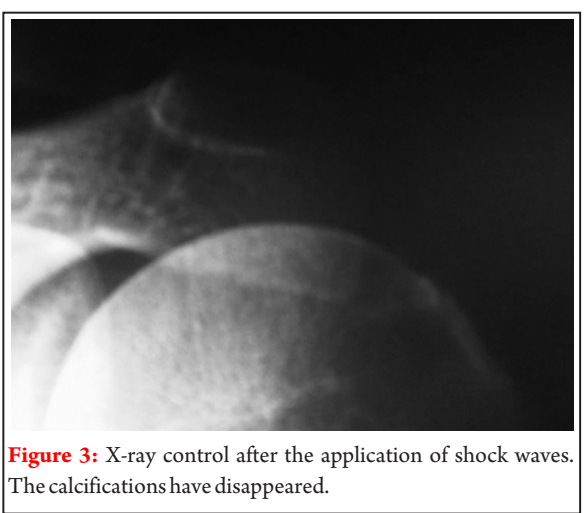

Dubs [39] compared the costs and effectiveness of shock wave therapy and standard treatments in Switzerland. Shock wave therapy was more effective and also saved an average of U\$S 2,500. The direct cost of arthroscopic treatment was 6.4 times higher than that of shock wave therapy, in a study carried out in Brazil by Eid [40].

The results of cost analysis presented by us at the 13th International Congress of Shoulder and Elbow Surgery in 2016 [41], also showed that shock waves costs were 5 to 7 times lower, representing savings around $2.000 €$ per patient when compared to arthroscopic surgery.

It has also been shown that the correct application of shock waves does not generate damage [42] and even when the desired therapeutic result is not obtained, its use does not alter the results of future surgery [43].

The use of F-ESWT in rotator cuff calcifications has been shown to have an $\mathrm{A}$ grade of recommendation [13]. This implies that based on published information, surgeons should change their practice [44].

Our case shows that focused shock waves might be a valid alternative in patients with rotator cuff injuries in whom the calcium deposit has not been completely removed with surgery. Associated injuries, complications of surgery ranging from infection to lack of healing of the rotator cuff and the need for acromioplasty should be ruled out.

\section{Conclusion}

The effectiveness of shock waves, their noninvasiveness, safety, and cost efficiency justify their use both as a rescue procedure and as an option before an invasive technique in the treatment of rotator cuff calcifications. 
Declaration of patient consent: The authors certify that they have obtained all appropriate patient consent forms. In the form, the patient has given his consent for his images and other clinical information to be reported in the Journal. The patient understands that his name and initials will not be published, and due efforts will be made to conceal his identity, but anonymity cannot be guaranteed.

Conflicts of Interest: Nil. Source of Support: None.

\section{References}

1. Bosworth BM. Calcium deposits in the shoulder and subacromial bursitis a survey of 12, 122 shoulders. JAMA 1942;116:2477-82.

2. Ruttiman G. Uber die Haufigkeit rontgenologischer Veranderungen bei Patienten mit Typischer Periarthritis Humeroscapularis und Schultergesunden. Zurich: Inaugural Dissertation; 1959.

3. Codman EA. The Shoulder: Rupture of the Supraspinatus Tendon and Other Lesions in or About the Subacromial Bursa. Boston: Thomas Todd Company; 1934.

4. Hajiroussou VJ, Webley M. Familial calcific periarthritis. Ann Rheum Dis 1983;42:469-70

5. De Sèze S, Welfling J. Tendinites calcifiantes. Rhumatologie 1970;22:45-50.

6. Sengar DP, McKendry RJ, Uhthoff HK. Increased frequency of HLA-A1 in calcifying tendinitis. Tissue Antigens 1987;29:173-4.

7. Oliva F, Barisani D, Grasso A, Maffulli N. Gene expression analysis in calcific tendinopathy of the rotator cuff. Eur Cell Mater 2011;21:548-57.

8. Chaudhury S, Carr AJ. Lessons we can learn from gene expression patterns in rotator cuff tears and tendinopathies. J Shoulder Elbow Surg 2012;21:191-9.

9. Herberts $P$, Kadefors $R$, Högfors $C$, Sigholm G. Shoulder pain and heavy manual labor. Clin Orthop Relat Res 1984;19:166-78.

10. Mavrikakis ME. Calcific shoulder periarthritis (tendinitis) in adult onset diabetes mellitus: A controlled study. J Bone Joint Surg 2005;87-B:162.

11. Harvie P. Calcific tendinitis: Natural history and association with endocrine disorders. J Bone Joint Surg 2005;87-B:162.

12. Uhthoff HK, Sarkar K, Maynard JA. Calcifying tendinitis: A new concept of its pathogenesis. Clin Orthop Relat Res 1976;118:164-8.

13. Moya D, Ramón S, Schaden W, Wang CJ, GuiloffL, Cheng JH. The role of extracorporeal shockwave treatment in musculoskeletal disorders. J Bone Joint Surg Am 2018;100:251-63.

14. Neer CS. Shoulder Reconstruction. Philadelphia, PA: WB Saunders; 1990. p. 43.

15. Gschwend N, Patte D, Zippel J. Therapy of calcific tendinitis of the shoulder. Arch Orthop Unfallchir 1972;73:120-35.

16. Wittenberg RH, Rubenthaler F, Wölk T, Ludwig J, Willburger RE, Steffen $R$. Surgical or conservative treatment for chronic rotator cuff calcifying tendinitis-a matched-pair analysis of 100 patients. Arch Orthop Trauma Surg 2001;121:56-9.

17. Maier D, Jaeger M, Izadpanah K, Bornebusch L, Suedkamp NP, et al. Rotator cuff preservation in arthroscopic treatment of calcific tendinitis. Arthroscopy 2013;29:824-31.

18. Litchman HM, Silver CM, Simon SD, Eshragi A. The surgical management of calcific tendinitis of the shoulder. Int Surg 1968;50:474-82.

19. McKendry RJ, Uhthoff HK, Sarkar K, Hyslop PS. Calcifying tendinitis of the shoulder: Prognostic value of clinical, histologic, and radiologic features in 57 surgically treated cases. J Rheumatol 1982;9:75-80.

20. Ark JW, Flock TJ, Flatow EL, Bigliani LU. Arthroscopic treatment of calcific tendinitis of the shoulder. Arthroscopy 1992;8:183-8.

21. Klein W, Gassen A, Laufenberg B. Endoskopische subacromiale dekompression und tendinitis calcarea. Arthoskopie 1992;5:247-51.

22. Lee TK, Shin SJ. Functional recovery of the shoulder after arthroscopic treatment for chronic calcific tendinitis. Clin Shoulder Elb 2018;21:75-81.

23. Balke M, Bielefeld R, Schmidt C, Dedy N, Liem D. Calcifying tendinitis of the shoulder: Midterm results after arthroscopic treatment. Am J Sports Med 2012;40:657-61.

24. Cho CH, Bae KC, Kim BS, Kim HJ, Kim DH. Recovery pattern after arthroscopic treatment for calcific tendinitis of the shoulder. Orthop Traumatol Surg Res 2020;106:687-91.
25. Verhaegen F, Brys $P$, Debeer P. Rotator cuff healing after needling of a calcific deposit using platelet-rich plasma augmentation: A randomized, prospective clinical trial. J Shoulder Elbow Surg 2016;25:169-73.

26. Wilson WK, Field LD. Management strategies for rotator cuff defects after calcific tendinitis debridement. Arthrosc Tech 2019;8:e1051-5.

27. Uththoff $H$, Loehr JW. Calcific tendinopathy of the rotator cuff: Pathogenesis, diagnosis and management. J Am Acad Orthop Surg 1997;5:183-91.

28. Weber SC. Arthroscopic Treatment of Calcific Tendinitis AANA 17th Annual Fall Course Palm Desert; 1998.

29. Yoo JC, Park WH, Koh KH, Kim SM. Arthroscopic treatment of chronic calcific tendinitis with complete removal and rotator cuff tendon repair. Knee Surg Sports Traumatol Arthrosc 2010;18:1694-9.

30. Ellman H, Bigliani LU, Flatow E, Esch IC, Snyder SJ, Oglivie-Harris D, et al. Arthroscopic Treatment of Calcifying Tendinitis: The American Experience. Paris, France: Presented, 5th International Conference on Shoulder Surgery; 1992.

31. Maier D, Jaeger M, Izadpanah K, Köstler W, Bischofberger AK, Südkamp NP, et al. Arthroscopic removal of chronic symptomatic calcifications of the supraspinatus tendon without acromioplasty: Analysis of postoperative recovery and outcome factors. Orthop J Sports Med 2014;2 (5):1-9. doi: 10.1177/2325967114533646

32. Moya D, Ramón S, Guiloff L, Gerdesmeyer L. Current knowledge on evidence-based shockwave treatments for shoulder pathology. Int $J$ Surg 2015;24:171-8

33. Gerdesmeyer L, Wagenpfeil S, Haake M, Maier M, Loew M, Wortler K, et al. Extracorporeal shock wave therapy for the treatment of chronic calcifying tendonitis of the rotator cuff: A randomized controlled trial. JAMA 2003;290:2573-80.

34. Cosentino R, De Stefano R, Selvi E, Frati E, Manca S, Frediani B, et al. Extracorporeal shock wave therapy for chronic calcific tendinitis of the shoulder: Single blind study. Ann Rheum Dis 2003;62:248-50.

35. Hsu CJ, Wang DY, Tseng KF, Fong YC, Hsu HC, Jim YF. Extracorporeal shock wave therapy for calcifying tendinitis of the shoulder. J Shoulder Elbow Surg. 2008;17:55-9.

36. Louwerens JK, Sierevelt IN, van Noort A, van den Bekerom MP. Evidence for minimally invasive therapies in the management of chronic calcific tendinopathy of the rotator cuff: $A$ systematic review and metaanalysis. J Shoulder Elbow Surg 2014;23:1240-9.

37. Rompe JD, Zoellner J, Nafe B. Shock wave therapy versus conventional surgery in the treatment of calcifying tendinitis of the shoulder. Clin Orthop Relat Res 2001;387:72-82.

38. Rebuzzi E, Coletti N, Schiavetti S, Giusto F. Arthroscopy surgery versus shock wave therapy for chronic calcifying tendinitis of the shoulder. $J$ Orthop Traumatol 2008;9:179-85.

39. Dubs B. Efficacy and Economical Aspects: Comparison ESWT Versus Alternate Therapies in the Treatment of Calcifying Tendinitis. Orlando: 6th Congress of the International Society for Musculoskeletal Shockwave Therapy; 2003.

40. Eid J. Economic aspects in the treatment of tendinosis calcarea of the shoulder. In: 9th International Congress of the International Society for Musculoskeletal Shockwave Therapy; 2006.

41. Ramon S, Moya D, Alvarez P, Cugat R, Corbella X. Efficiency in the Treatment of Calcifying Tendinopathy of the Shoulder: Extracorporeal Shockwave Therapy vs. Surgery. Jeju, Korea: 13th International Congress of Shoulder and Elbow Surgery; 2016.

42. Cyteval C, Baron-Sarrabère MP, Jorgensen C, Cottin A, Benis J, Sany $J$, et al. MRI study before and after extracorporal shock wave therapy in calcifying tendinitis of the shoulder. J Radiol 2003;84:681-4.

43. Lorbach O, Kusma M, Pape D, Kohn D, Dienst M. Influence of deposit stage and failed ESWT on the surgical results of arthroscopic treatment of 
calcifying tendonitis of the shoulder. Knee Surg Sports Traumatol Arthrosc 2008;16:516-21.
44. Wright JG. Revised grades of recommendation for summaries or reviews of orthopaedic surgical studies. J Bone Joint Surg Am 2006;88:1161-2

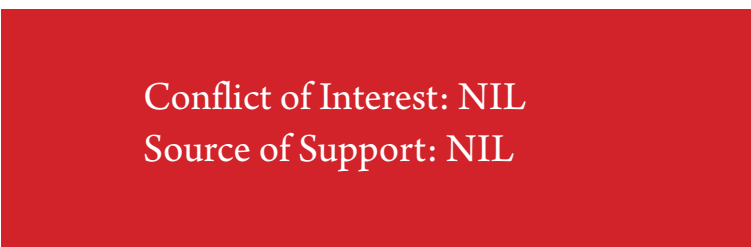

\section{How to Cite this Article}

Moya D | Case Report: Focused Shock Waves as a Treatment Option in Failed Rotator Cuff Calcification Surgery | Journal of Regenerative Science | December $2021 ; 1(1): 51-54$. 